\title{
Magnitude and Pattern of Inpatient Surgical Mortality in a Tertiary Hospital in Addis Ababa, Ethiopia
}

\author{
Firaol Dandena ${ }^{1}$, Belayneh Leulseged ${ }^{2}$, Yisihak Suga $^{3}$, Berhanetsehay \\ Teklewold $^{3 *}$
}

\footnotetext{
OPEN ACCESS

Citation: Firaol Dandena, Belayneh Leulseged, Yisihak Suga, Berhanetsehay Teklewold. Magnitude and Pattern of Inpatient Surgical Mortality in Saint Paul's Hospital Millennium Medical College: Addis Ababa, Ethiopia: A Three Years' Retrospective Review. Ethiop J Health Sci. 2020;30(3):371.doi: http://dx.doi.org/10.4314/ejhs.v30 i3.8 Received: November 14, 2019

Accepted: December 29, 2019 Published: May 1, 2020

Copyright: (C2020 Firaol Dendena, et al. This is an open access article distributed under the terms of the Creative Commons Attribution License, which permits unrestricted use, distribution, and reproduction in any medium, provided the original author and source are credited. Funding: Nil

Competing Interests: The authors declare that this manuscript was approved by all authors in its form and that no competing interest exists.

Affiliation and Correspondence:

1St. Paul's Hospital Millennium Medical College, Addis Ababa, Ethiopia

${ }^{2}$ Department of Public Health, St Paul Hospital Millennium Medical College, Addis Ababa, Ethiopia 3Department of Surgery, St Paul hospital Millennium Medical College, Addis Ababa, Ethiopia *Email:

berhanetsehay.teklewold@sphmmc. edu.et
}

\begin{abstract}
BACKGROUND: Inpatient mortality is among regularly collected data in Key performance indicators in the Ethiopian healthcare system, and it is generally reported to the Federal Ministry of Health and is used as one of inpatient services quality indicators. This study was undertaken to identify the magnitude, causes and pattern of mortalities among patients who are admitted and treated in surgical wards in Saint Paul Hospital Millennium Medical College for a period of three years.
\end{abstract}

METHODS: A retrospective review was done on all patients admitted and died in the Department of Surgery in St. Paul's Hospital Millennium Medical College from January 1, 2016-Dec 30, 2018.

RESULT: There were 10,259 admissions over three years and out of which there were 350 deaths between 2016-2018 making a crude mortality rate of $3.41 \%$. The commonest mode of admission was for emergency conditions, 195(62.7\%). Out of emergency admissions, 139 mortalities were from general emergency surgery and 75 patients died from elective general surgery admissions. Eighty-four (26.9\%) patients had comorbidity and the commonest comorbidity was anemia 21(25\%). The commonest possible cause of death was multi-organ failure secondary to septic shock, 159(51\%). Mortality rate patterns along the three years $(2016,2017,2018)$ showed $3.34 \%$ (112/3360), 2.87\% (102/3552) and 2.92\% (98/3347) respectively.

CONCLUSION: The mortality rate of this study is much higher than global rates, but still there is a significant difference from other developing countries and also other researches in this country. Pattern of mortality did not show any difference across years of the study period.

KEYWORDS: Inpatient mortality, surgical mortality, and pattern

\section{INTRODUCTION}

Surgical care is an integral part of healthcare throughout the world with an estimated 234 million operations performed annually. Approximately 4,000 surgical procedures per 100,000 populations in many countries and up to 11,000 procedures per 100,000 populations are carried out in high volume countries annually. Although surgical care can improve the quality of life and prevent loss of life or limb, it 
is also associated with considerable risk of complications and death (1). The Lancet Commission on Global Surgery has established six indicators to indicate the success of providing access to safe and affordable surgery one of which is inpatient surgical mortality (2).

Morbidities and mortalities in surgery are common scenarios seen by surgeons and other healthcare providers along with their practice. Hospitals and departments in particular regularly analyze reports in mortalities to know possible causes and factors associated with it to devise strategies to prevent or to minimize this from happening (3). Surgical mortalities occur for several reasons, and a study of causes and patterns may help in bridging the knowledge gap in the surgical setting. It can also identify areas that require more improvement, practice modification and policy formulations (4).

The global incidence of postoperative mortality is estimated to be $4 \%$, but data describing surgical outcomes in developing countries like ours are few. Though unconfirmed, it is believed that perioperative mortality is significantly high in African setups $(5,6)$. African surgical outcomes study (ASOS) has shown that, though patients in Africa are fortunate enough to access surgical care, the patient outcomes following surgery are relatively poor. ASOS demonstrated that African surgical patients were twice as likely to die following surgery when compared to the global average, despite a similar complication rate to the global average (7).

Incidence of postoperative mortality in neighboring countries as to the reports in few researches is considerably high ranging from $5.09 \%$ to $9.14 \%$ in Nigeria $(8,9)$. Only one research was found in Ethiopia, which describes postoperative mortality in Black Lion Hospital to be $7 \%$ (10).Therefore, this study tried to assess the magnitude and patterns of mortality on patients who died at surgical wards in St Paul's Hospital Millennium Medical College from January 1, 2016, to Dec 30, 2018. The result of this study thus will help in understanding the magnitude of death in surgical wards and its pattern along years. All patients who were admitted to either general surgery, urology or pediatric surgery units were included in the study. Mortality count includes those who were treated either by operation or nonoperatively. Surgical mortalities in other departments other than the three mentioned are not included in the study. The findings of the study will help in improving quality in surgical care by identifying possible causes of death

\section{METHODS}

Study area: This study was conducted at St Paul's Hospital Millennium Medical College, Addis Ababa, Ethiopia. This hospital is located at the northwest of Addis Ababa and it is one of the largest tertiary hospitals in the city. It has many catchment area health centers from where different complicated cases are referred. The Department of Surgery is among the bigger departments in the hospital with 90 beds for inpatient care; it also gives outpatient surgical services. Department of Surgery in Saint Paul is organized in three units with the largest being general surgery and two other units are urology and pediatrics surgery with their respective wards, staff, and operative services. Department of Neurosurgery and Orthopedics which were part of the general surgery are currently located in other trauma specialized center in Addis Ababa before the last four years.

\section{Study period}

Data of mortality from January 1, 2016, to Dec 30, 2018 among surgical patients were collected from February 4, 2019, to March 13, 2019.

Study design: We conducted retrospective review of patients' records who died in the department of surgery between January 1, 2016, to Dec 30, 2018.

Study population: All patients who were admitted and died at surgical wards from January 1, 2016, to Dec 30, 2018 were included in the study.

Exclusion criteria: Incomplete Information in ward registration books such as cause of death and All patients who died in emergency units though diagnosed to have surgical pathology but who were not admitted to surgical wards were excluded. Mortalities in other departments other than the three units were not included in the study.

Sample size: Single population proportion and 95\% confidence level, margin of error 5\% and unknown proportion was used to get maximum sample size. Three years' mortality was collected to get this size and therefore all patients who died at surgical wards

DOI: http://dx.doi.org/10.4314/ejhs.v30i3.8 
from January 1, 2016, to Dec 30, 2018 were included in the study and the sample size was 350 .

Data collection tool and procedures: The Data were extracted from ward registration books of patients admitted to the surgical wards, OR logbooks and department monthly morbidity and mortality reports. Collected data were crosschecked with the hospital HMIS report. Extracted data included age, gender, ethnicity, religion and address, surgical diagnosis, co-morbid conditions, type of admissions, the procedure performed, and events leading to death, dates of death and possible cause of death. All the above data was recorded on a prepared format which was adapted from infection classification of disease (ICD).

Data analysis: Data were coded, entered and cleaned using SPSS version 24 software package by the principal investigator. Simple descriptive statistics such as frequencies distribution were done as appropriate, and the result was presented in tables and graphs.

Ethical consideration

Ethical clearance was obtained from the Institutional Review Board (IRB) of St. Paul's Hospital Millennium Medical College. The personal information of study participants was kept entirely anonymous, and confidentiality was assured throughout the study period. The data was used only for the purpose of the study.

\section{RESULTS}

Socio-demographic profile: Between the 3-year study period (January $1 / 2016$ to Dec 30,2018 ), there were 10,259 surgical admissions in the Department of Surgery, and $38 \%$ of all these admissions was for emergency conditions. Among this, a total of 350 patients died in the study period. From these mortalities, 37 patients' charts were excluded for incompleteness yielding 312 deaths with crude mortality rate being $3.41 \%(350 / 10259)$.

Out of 312 dead patients, 204(66.6\%) were males and $108(33.4 \%)$ were females with male to female ratio of 2:1. The majority of mortalities were among the age group of between 25 to 54 which accounts for $120(38.4 \%)$, followed by age groups above 65 years $98(31.4 \%)$ and the least percentage of mortality was seen in the age groups less than 14 years of age $10(3.2 \%)$. The proportion of patients from rural and urban areas was comparable $154(49.4 \%)$ and $158(50.6 \%)$ respectively (Table 1$)$.

Clinical profile: The commonest mode of admission was for emergency surgical conditions $195(62.5 \%)$ and $117(37.3 \%)$ patients were admitted for elective procedures. Mortality among emergency admissions was 5\% (195/3898).

Out of the total mortalities, general surgery accounted for 214(68.6\%) and 83(26.6\%), and $15(4.8 \%)$ deaths were of urologic and paediatric pathology respectively. Mortality rates at three of the units in the ward (general surgery, urology, paediatrics) units showed 3.26\% (214/6562), 3.83\% (83/2165), 0.98\% (15/1532) respectively.

Out of mortalities in general surgery, the majority of deaths, $64.9 \%$ (139/214), were admitted on emergency bases and the commonest cause of emergency admission was intestinal obstruction, 42(19.6\%), followed by peritonitis 36(16.8\%).

Out of the total, 75 (35\%) death accounted for elective General surgery and hepatobiliary pathology was the commonest admission diagnosis in $35(46.7 \%)$, followed by colo-rectal pathology 12(16\%) (Table 2).

DOI: http://dx.doi.org/10.4314/ejhs.v30i3.8 
Table 1: Sociodemographic characteristics of patients who died at surgical wards, SPHMMC from January 1/2016 to Dec 30, 2018(n=312).

\begin{tabular}{llll}
\hline Variables & Category & Frequency & Percent (\%) \\
\hline Age & $0-14$ & 10 & 3.2 \\
& $15-24$ & 24 & 7.6 \\
& $25-54$ & 120 & 38.4 \\
& $55-64$ & 60 & 19.2 \\
& $65^{+}$ & 98 & 31.4 \\
Sex & Total & 312 & 100 \\
& Male & 204 & 65.4 \\
Address & Female & 108 & 34.6 \\
& Urban & 158 & 50.6 \\
& Rural & 154 & 49.4 \\
\hline
\end{tabular}

Table 2: General surgery admission diagnosis of patients who died at general surgical wards, SPHMMC from January $1 / 2016$ to Dec 30, 2018 G.C ( $n=214)$.

\begin{tabular}{llll}
\hline $\begin{array}{l}\text { General surgery } \\
\text { admission }\end{array}$ & Diagnosis & Frequency & $\begin{array}{l}\text { Percent (\%) } \\
\text { n=214 }\end{array}$ \\
\hline Elective & Hepatobiliary Pathology & 35 & 16.3 \\
& Colo-rectal cancer & 12 & 5.6 \\
Gastric cancer & 7 & 3.3 \\
Benign perianal conditions & 4 & 1.9 \\
& Hernia & 2 & 0.9 \\
colostomy reversal & 2 & 0.9 \\
pancreatic cancer & 2 & 0.9 \\
psoas abscess & 2 & 0.9 \\
Retroperitoneal mass & 2 & 0.9 \\
& others* & 7 & 3.2 \\
Total & 75 & 35 \\
Emergency & & \\
& Intestinal obstruction & 42 & 19.6 \\
& Peritonitis & 36 & 16.8 \\
Hepatobiliary Infections & 19 & 8.9 \\
post-op complication & 7 & 3.3 \\
Abdominal injury & 7 & 3.3 \\
Appendicitis\& complication & 7 & 3.3 \\
Fournier gangrene & 8 & 3.7 \\
Entro -cutaneous fistula & 7 & 3.3 \\
Intra-abdominal bleeding & 2 & 0.9 \\
Others** & 4 & 1.9 \\
Total & & 65 \\
\hline
\end{tabular}

*Others oesophageal cancer, gangrene, gluteal abscess, liver abscess, scrotal abscess, splenic abscess and gangrene

** Others bladder rupture, eviscerated bowel, retained foreign body and upper airway obstruction

Out of 15 deaths in pediatrics surgery, $8(53.3 \%) \quad 7(46.7 \%)$ were admitted for pediatrics emergency were admitted for pediatrics elective surgery and (Table 3).

DOI: http://dx.doi.org/10.4314/ejhs.v30i3.8 
Table 3: Paediatrics surgical patients who died at pediatrics surgical ward, SPHMMC from January 1/2016 to Dec 30, 2018 G.C ( $\mathrm{n}=15)$

\begin{tabular}{llll}
\hline $\begin{array}{l}\text { Pediatric } \\
\text { admission }\end{array}$ & Diagnosis & Frequency & Percent (\%)n=15 \\
\hline Elective & Infantile hypertrophic pyloric stenosis & 4 & 26.7 \\
& (IHPS) & 4 & 26.7 \\
Emergency & Hirshusprungs disease (HD) & 3 & 20 \\
& Appendicitis and its complications & 4 & 26.7 \\
& Bowel obstruction & & \\
\hline
\end{tabular}

Out of 83 mortalities in the urology unit, $46(56 \%)$ deaths were admitted for emergency and 36(44\%) were elective (Table 4). Only 84(26.9\%) deaths had comorbidity out of all deaths and the commonest comorbidity identified out of those with comorbidity was anemia, 21(25\%), (Table 5).

The commonest causes of mortalities identified were multi-organ failure secondary to septic shock,
159(51\%), respiratory failure, 56(16.3\%), massive venous thromboembolism, 30(9.0\%), sudden cardiac arrest, 28(8.4\%), and Uremia, 8(2.4\%) (Figure 1). Mortality trends along the three years showed 3.33\% (112/3360), $2.87 \%(102 / 3552)$ and $2.92 \%(98 / 3347)$ respectively.

Table 4: Urology surgical patients who died at urology ward, SPHMMC from January 1/2016 to Dec 30, 2018 G.C $(n=83)$.

\begin{tabular}{llll}
\hline Urologic admission & Diagnosis & Frequency & Percent $(\%) \mathrm{n}=83$ \\
\hline Elective & Benign prostatic hyperplasia(BPH) & 20 & 24 \\
& Stone disease & 5 & 6 \\
& Urethral stricture & 4 & 4.8 \\
& Bladder tumor & 4 & 4.8 \\
& Renal cell carcinoma & 2 & 2.4 \\
Emergency & Total & 35 & 42.2 \\
& Urosepsis & 7 & 8.4 \\
& Acute urinary retention(AUR) & 14 & 16.9 \\
& Obstructive uropathy & 27 & 32.5 \\
& Total & 48 & 57.8 \\
\hline
\end{tabular}

Table 5: Frequency of comorbidity of patients who died at surgical wards, SPHMMC from January 1/2016 to Dec 30, 2018 G.C ( $=84)$.

\begin{tabular}{lll}
\hline Comorbidity & Frequency & Percent (\%) \\
\hline Anemia & 21 & 25 \\
Hypertension & 18 & 21.4 \\
Diabetes Mellitus & 16 & 19 \\
Chronic Kidney Disease & 11 & 13.1 \\
Retro Viral Infection & 11 & 13.1 \\
Asthma & 4 & 4.8 \\
Acute kidney injury & 2 & 2.4 \\
pneumonia & 1 & 1.2 \\
Total & 84 & 100 \\
\hline
\end{tabular}

DOI: http://dx.doi.org/10.4314/ejhs.v30i3.8 


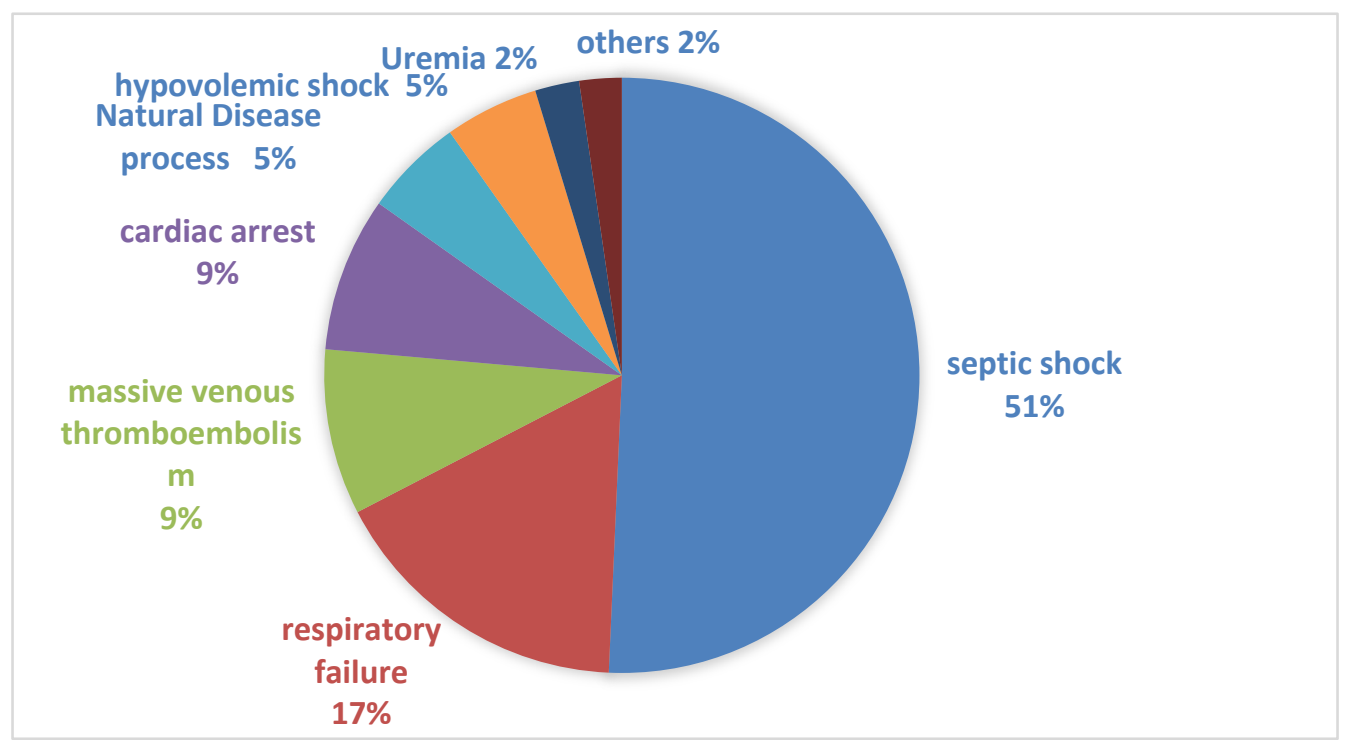

Figure 1: Possible Cause of death of patients who died at surgical wards, SPHMMC from January 1/2016Dec 30, 2019.

\section{DISCUSSION}

Surgical inpatient mortalities in our study included all patients who were admitted to surgical wards and managed both operatively and non-operatively. Surgical procedures performed in neurosurgery and burn units were not included in our study because patients who needed such procedures were referred to another affiliate center, which is located away from the hospital where the study was done. Exclusion of such patients greatly affects mortality burden and pattern as deaths related especially to head injury are missed.

The surgical mortality rate over the three years period of this study was $3.41 \%$, which is relatively low compared to other reports from similar studies in Africa which show the higher rate of mortality ranging from $5.09 \%$ to $9.14 \%$ in Nigeria $(8,9,11,12)$ which is more than twice the rate our study revealed. The study in Black Lion Hospital in Ethiopia, which is one of the tertiary hospitals in the country, also showed rate of 7\% (10) which again is twice our result but the reason can be the inclusion of neurosurgical patients in their study which our study does not include. This might have affected the magnitude of the death and also patients with burn injury are not included in our study as these patients are not managed in the department of surgery in the study period. However when compared to the rates in developed countries, our result shows significantly high number. Studies showed that mortality rates lie between $0.4 \%$ and $0.8 \%$ in developed countries (13).

Emergency procedures are known to be associated with higher mortality which can be as high as $5.8 \%$ when compared to elective which is less than 1 percent according to findings from Ingraham et.al (14).Some of the reasons described for such high figures were inadequate resuscitation time, physiologic derangement of patients and the like. In our study also, the majority of mortalities were from emergency admission (5\%). Mortalities during an emergency can be minimized with proper resuscitation, preoperative preparation of patients before the operative procedure, timely decision on surgical intervention and meticulous follow-up of sterility techniques to reduce infections postoperatively.

Only $27 \%$ of the patients had comorbidity in our study, but similar studies in Australia and Brazil showed significantly high percentage of comorbidity $(91 \%)$ that have highly increased the risk of death $(11,15)$. Reason for such huge discrepancy can be attributed to differences in mean age groups and associated advances in healthcare technology in developed countries that helps greatly in preoperative screenings. Among the comorbidities mentioned, anemia accounted for one-fourth, which is also similar to the study done in Brazil by Stahlschmidt A et.al (16).

Trends along the three years in our study do not show a reduction in crude mortality rates. Except for mortalities in pediatrics, mortality rates in general surgery and urology are comparable across the years. The mortalities observed in all units are described as gross and it is difficult for surgeons to learn from such figures, as this does not differentiate mortalities related to specific causes. Mortalities should also be adjusted to reflect nonviable and viable patient mortalities as reported by

DOI: http://dx.doi.org/10.4314/ejhs.v30i3.8 
researches done to standardize mortalities. Data presented in such a way would help surgeons and physicians who are seeking ways of improving the services provided to surgical patients (17).

In conclusion, the mortality rate of this study is much higher than global rates, but still, there is a significant difference from other developing countries or other researches in this country. Acute abdomen is a major contributor to mortality among our surgical inpatients and septicemia is the most common cause of death. Over the study period, no reduction in death rate was observed. The finding of this research will highlight the importance of doing further research in identifying standardized mortality ratios to correctly compare with other similar studies.

\section{ACKNOWLEDGMENT}

We would like to thank St. Paul's Hospital Millennium Medical College for the financial support for the study.

\section{REFERENCES}

1. Weiser TG, Regenbogen SE, Thompson KD, Haynes AB, Lipsitz SR, Berry WR, et.al. An estimation of the global volume of surgery: a modelling strategy based on available data. The Lancet. 2008 Jul 12;372(9633):139-44.

2. Ng-Kamstra JS, Greenberg SL, Abdullah F, Amado V, Anderson GA, Cossa M, et.al: Global Surgery 2030: a roadmap for high income country actors. BMJ Global Health. 2016 Apr 1; 1(1):e000011.

3. Bindroo S, Saraf R. Surgical Mortality Auditlessons learned in a Developing Nation. International surgery. 2015 Jun; 100(6):1026-32.

4. Ayoade BA, Thanni LO, Shonoiki-Oladipupo O. Mortality pattern in surgical wards of a university teaching hospital in southwest Nigeria: a review. World journal of surgery. 2013 Mar 1;37(3):504-9.

5. Bainbridge D., Martin J, Arango M, Cheng D, Evidence-based Peri-operative Clinical Outcomes Research (EPiCOR) Group. Perioperative and anaesthetic-related mortality in developed and developing countries: a systematic review and metaanalysis. Lancet. 2012; 380:1075-81.

6. Grimes CE, Billingsley ML, Dare AJ, Day N, George PM, Kamara TB, et.al. The demographics of patients affected by surgical disease in district hospitals in two sub-Saharan African countries: a retrospective descriptive analysis. SpringerPlus. 2015 Dec 1;4(1):750.

7. Biccard BM, Madiba TE, Kluyts HL, Munlemvo DM, Madzimbamuto FD, Basenero A, et.al.
Perioperative patient outcomes in the African Surgical Outcomes Study: a 7-day prospective observational cohort study. The Lancet. 2018 Apr 21;391 (10130):1589-98.

8. Ayoade BA, Thanni LO, Shonoiki-Oladipupo O. Mortality pattern in surgical wards of a university teaching hospital in southwest Nigeria: a review. World journal of surgery. 2013 Mar 1;37(3):504-9.

9. Chukuezi AB, Nwosu JN. Mortality pattern in the surgical wards: a five-year review at Federal Medical Centre, Owerri, Nigeria. International Journal of Surgery. 2010 Jan 1;8(5):381-3.

10. Biluts H, Bekele A, Kottiso B, Enqueselassie F, Munie T. In-patient surgical mortality in Tikur Anbessa Hospital: a five-year review. Ethiopian Medical Journal. 2009 Jan;47(2):135-42.

11. Ihegihu CC, Chianakwana GU, Ugezu T, Anyanwu SN. A review of in-hospital surgical mortality at the Nnamdi Azikiwe University Teaching Hospital Nnewi, Nigeria. Tropical Journal of Medical Research. 2007;11(2):26.

12. Onyemaechi NO, Popoola SO, Schuh A, Iorbo AT, Elachi IC, Oluwadiya KS. Mortality pattern of hospitalized surgical patients in a Nigerian tertiary hospital. Indian Journal of Surgery. 2015 Dec 1;77(3):881-5.

13. Debas HT, Gosselin R, McCord C, Thind A. Surgery. In: Jamison DT, Breman JG, Measham $\mathrm{AR}$, et al., eds. Disease control priorities in developing countries. 2nd ed. Disease Control Priorities Project. Washington, DC: International Bank for Reconstruction and Development/World Bank, 2006:1245-60.

14. Ingraham AM, Cohen ME, Raval MV, Ko CY, Nathens AB. Comparison of hospital performance in emergency versus elective general surgery operations at 198 hospitals. Journal of the American College of Surgeons. 2011 Jan 1;212(1):20-8.

15. Semel ME, Lipsitz SR, Funk LM, Bader AM, Weiser TG, Gawande AA. Rates and patterns of death after surgery in the United States, 1996 and 2006. Surgery. 2012 Feb 1;151(2):171-82.

16. Stahlschmidt A, Novelo B, Freitas LA, Passos SC, Dussán-Sarria JA, Félix EA, et.al. Predictors of inhospital mortality in patients undergoing elective surgery in a university hospital: a prospective cohort. Revista brasileira de anestesiologia. 2018 Oct;68(5):492-8.

17. Seymour DG, Pringe R. A new method of auditing surgical mortality rates: application to a group of elderly general surgical patients. BMJ May 1982;284:1539-42. 
